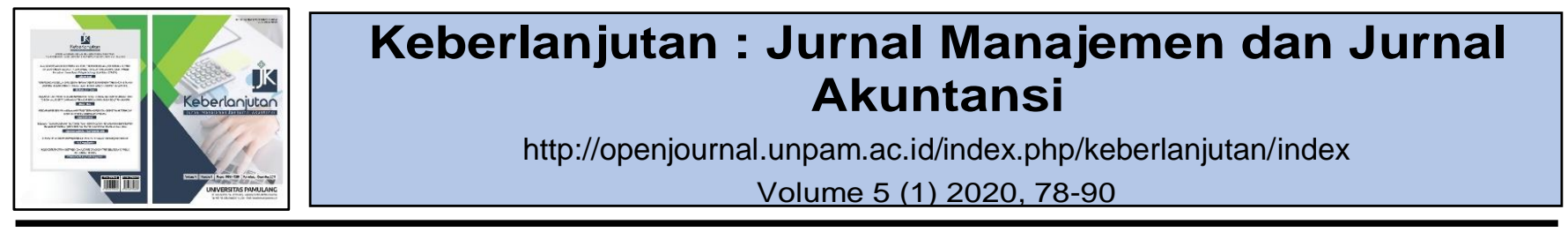

\title{
Pemetaan Penelitian Terkait Implementasi IFRS 15 Tentang Pendapatan dari Kontrak dengan Pelanggan \\ Amardianto Arham ${ }^{1}$, Doni Habibur Rahman², Firdiyawan Lisdiyanto ${ }^{3}$
}

1,2,3 Politeknik Keuangan Negara STAN, Indonesia

\begin{tabular}{l}
\hline Article Info \\
\hline Article history: \\
Received:2020-06-23; \\
Accepted:2020-06-28; \\
Published:2020-07-15;
\end{tabular}

Kata Kunci:

IFRS 15, Pemetaan

Pendapatan, Pendapatan

\begin{abstract}
This study aims to map various research results related to implementation of IFRS 15 about Revenue from Contracts with Customers in order to find out the focus of research all over the world in terms of location of research object, research topics (perceptions, impacts, and problems), and position (pros/cons) toward this standard. This study uses a qualitative method with a bibliographic approach. The objects used in this study are 22 research articles about implementation of IFRS 15. The results of mapping analysis show that the most discussed research topic is the impact. The focus of research that uses the topic of impact and perception is the preparers of financial statements. Meanwhile, research that uses the topic of problem has provided perspective from two sides (the preparers and the users of financial statements). The results of mapping analysis show that majority of the position of the research object toward the implementation of IFRS 15 is still unclear because it shows that the position is on two sides, the pros and cons.
\end{abstract}

\begin{abstract}
Abstrak
Penelitian ini bertujuan untuk memetakan berbagai hasil penelitian terkait implementasi IFRS 15 tentang Pendapatan dari Kontrak dengan Pelanggan agar dapat mengetahui fokus penelitian di berbagai negara di dunia baik yang ditinjau dari segi topik penelitian (persepsi, dampak, dan masalah) maupun sikap (pro/kontra) terhadap standar ini. Penelitian ini menggunakan metode kualitatif dengan pendekatan bibliografi. Objek penelitian ini adalah 22 artikel penelitian mengenai implementasi IFRS 15. Hasil analisis pemetaan menunjukkan bahwa topik penelitian yang paling banyak dibahas adalah tentang dampak. Penelitian dengan topik dampak dan persepsi lebih berfokus pada pembuat laporan keuangan. Adapun penelitian dengan topik masalah telah memberikan sudut pandang dari dua sisi (pembuat dan pengguna laporan keuangan). Hasil analisis pemetaan menunjukkan bahwa mayoritas sikap objek penelitian terhadap implementasi IFRS 15 masih belum jelas karena menunjukkan sikap berada di dua sisi yaitu pro dan kontra.
\end{abstract}

\footnotetext{
Cara mengutip:

Arham, A., Rahman, D. H., \& Lisdiyanto, F. (2020). Pemetaan Penelitian Terkait Implementasi IFRS 15 tentang Pendapatan dari Kontrak dengan Pelanggan. Keberlanjutan : Jurnal Manajemen dan Jurnal Akuntansi, 5 (1), 78-90
}

Email Penulis.

arhamamardianto@gmail.com / Amardianto Arham
ISSN: 2614-3291 (online) http://dx.doi.org/10.32493/keberlanjutan.v5i1.y2020.p78-90 


\section{PENDAHULUAN}

Laporan keuangan berguna bagi investor dan kreditor karena memberikan informasi keuangan yang dapat digunakan untuk menilai kinerja entitas dan mengambil keputusan terkait pemberian sumber daya kepada entitas (DSAK-IAI, 2015). Dalam proses penyusunan serta penyajian informasi keuangan bagi pengguna eksternal, prinsip dan aturan umum akuntansi mempunyai peran penting (Ahmed et al., 2013).

Berkembangnya pasar global mendorong adanya kebutuhan akan standar akuntansi yang bersifat universal serta dapat diterapkan secara internasional sehingga meningkatkan komparabilitas dan kualitas laporan keuangan di pasar global (Yurisandy \& Puspitasari, 2015). Hal ini direspon oleh International Accounting Standard Board (IASB) dengan menerbitkan International Financial Reporting Standards (IFRS) pada tahun 2001. IFRS sebagai standar yang bersifat principle based diharapkan mampu meningkatkan kualitas, transparansi, serta komparabilitas laporan keuangan sehingga dapat mengurangi masalah dalam praktik akuntansi dan meminimalkan biaya untuk membandingkan risiko dan peluang investasi di pasar global (Daske, 2006).

Penggunaan IFRS memerlukan lebih banyak pengungkapan di dalam catatan atas laporan keuangan (Yaacob \& Che-Ahmad, 2012). Beberapa penelitian terdahulu memberikan bukti empiris bahwa ada beberapa masalah terkait proses implementasi IFRS. Evans et al. (2005) menemukan bahwa adanya perbedaan budaya dan bahasa dapat menjadi hambatan dalam penerapan IFRS. Sementara itu, Efferin \& Rudiawarni (2014) menganalisis hambatan implementasi IFRS di Indonesia dari sisi regulator, auditor, akuntan perusahaan, pembelajaran akuntansi dan pengguna laporan keuangan.

IFRS 15 sebagai standar pengakuan pendapatan merupakan hasil konvergensi IASB dan Financial Accounting Standard Board (FASB). Di Amerika Serikat, IFRS 15 identik dengan Accounting Standards Update (ASU) 606 dan diterbitkan pada tanggal 28 Mei 2014 (Pratama \& Wahyuni, 2015). Sementara itu, di Indonesia, IFRS 15 diadopsi menjadi PSAK 72 tentang Pendapatan dari Kontrak dengan Pelanggan melalui penerbitan Exposure Draft pada 23 November 2016 dan kemudian disahkan pada 26 Juli 2017 dengan pemberlakuan efektif mulai 1 Januari 2020 (http://iaiglobal.or.id).

Mulai 1 Januari 2020, perusahaan di Indonesia wajib menerapkan PSAK 72 yang menggantikan PSAK 23. Oleh karena itu, perusahaan perlu menyesuaikan laporan keuangannya agar memenuhi standar internasional tersebut. Perubahan mendasar dalam PSAK 72 adalah pemberlakuan standar tunggal atas pengakuan pendapatan bagi seluruh jenis industri (https://news.ddtc.co.id).

Sektor yang akan terkena efek dari perubahan standar akuntansi terkait pengakuan pendapatan yaitu sektor manufaktur, retail, industri konstruksi, serta telekomunikasi (International Accounting Standards Board, 2014). Penelitian lain menambahkan bahwa menurut International Accounting Standards Board (IASB) perubahan standar ini akan memberikan dampak yang signifikan terutama bagi perusahaan-perusahaan yang memiliki transaksi berupa kontrak jangka panjang atau produk gabungan yang biasanya ditemukan pada perusahaan real estate dan telekomunikasi (Ghaniy, 2018). PSAK 72 memberikan kerangka pengukuran pendapatan yang komprehensif dan konsisten. Penerapan standar ini akan mengubah pola pengakuan pendapatan yang berdampak besar pada laporan laba rugi yang dianggap sebagai salah satu laporan keuangan yang penting karena mengungkapkan kemampuan perusahaan dalam menghasilkan laba sehingga investor diprediksi akan terpengaruh terhadap adanya penerbitan PSAK ini (Wisnantiasri, 2018). Penerapan PSAK 72 dinilai masih menghadapi sejumlah hambatan yang memberatkan pengembang. Dalam PSAK 72, prestasi pengembang properti seperti tidak diapresiasi. Hal tersebut merugikan catatan dan aliran keuangan pengembang. Real Estate Indonesia (REI) telah melakukan diskusi dengan IAI, namun belum mendapatkan hasil atau solusi (https://ekonomi.bisnis.com).

Berdasarkan uraian mengenai dampak dan permasalahan yang mungkin ditemui dalam implementasi PSAK 72 yang merupakan adopsi IFRS 15 tersebut, perlu dilakukan pemetaan terkait hasil penelitian implementasi IFRS 15 yang dapat dijadikan panduan bagi para akademisi dalam penelitian selanjutnya atau para penyusun standar dalam pembuatan 
maupun adopsi standar akuntansi baru. Penelitian yang secara khusus memetakan hasil penelitian terkait implementasi IFRS 15 belum pernah dilakukan sebelumnya. Beberapa penelitian terdahulu hanya melakukan analisis untuk memetakan fokus penelitian terkait adopsi IFRS secara keseluruhan di suatu negara. Aksan et al. (2019) mengulas perkembangan penelitian terkait adopsi IFRS di Indonesia berdasarkan data sejumlah 35 artikel pada tahun 2003 sampai dengan tahun 2017. Selanjutnya, Ernawati \& Aryani (2019) juga melakukan pemetaan bukti empiris hasil penelitian terkait perkembangan IFRS di Indonesia dengan menganalisis 31 artikel pada tahun 2008-2017. Yang terakhir, Wahyuni et al. (2020) melakukan penelitian untuk menemukan pengaruh adopsi IFRS di Indonesia melalui studi literatur terhadap 168 artikel pada tahun 2010 sampai dengan 2016. Oleh karena itu, penelitian ini bertujuan untuk menganalisis dan memetakan berbagai hasil penelitian terkait implementasi IFRS 15 tentang Pendapatan dari Kontrak dengan Pelanggan. Pemetaan dilakukan untuk mengetahui bagaimana implementasi IFRS 15 di beberapa negara di dunia baik dari segi persepsi terkait adanya standar baru ini, dampak yang ditimbulkan, masalah yang dialami, hingga sikap (pro/kontra) terhadap standar ini.

\section{LANDASAN TEORITIS}

\section{Penyusunan IFRS 15 dan Adopsi Menjadi PSAK 72}

Proses penyusunan IFRS 15 diawali dengan pembuatan kesepakatan antara IASB dan FASB terkait pembentukan kelompok kerja yang disebut Transition Resource Group (TRG). Anggota TRG terdiri atas 27 orang yang berasal dari berbagai negara antara lain, Jepang, Kanada, Inggris, serta Brazil. Adapun Ketua TRG merupakan perwakilan dari IASB dan wakil ketua merupakan perwakilan dari FASB. TRG mengadakan rapat perdana pada bulan Juli 2014. Sejak saat itu, TRG sudah mengadakan pertemuan beberapa kali untuk membahas implementasi IFRS 15 sampai dengan November 2015. FASB kemudian melanjutkan rapat TRG hanya untuk Amerika Serikat dan melakukan klarifikasi terhadap IFRS 15 pada April 2016 (Pratama \& Wahyuni, 2015).

Sementara itu, di Indonesia, IFRS 15 tentang Pendapatan dari Kontrak dengan Pelanggan diadopsi menjadi PSAK 72 yang diawali dengan penerbitan Exposure Draft oleh DSAK IAI pada 23 November 2016. Kemudian pada tanggal 26 Juli 2017, DSAK IAI mengesahkan PSAK 72. Pada rapat tersebut, DSAK IAI juga menetapkan bahwa mulai 1 Januari 2020, PSAK 72 sudah berlaku efektif dan opsi untuk penerapan dini juga diberikan (http://iaiglobal.or.id).

\section{Ikhtisar Ringkas PSAK 72}

PSAK 72 adalah adopsi IFRS 15 tentang pendapatan dari kontrak dengan pelanggan yang telah diberlakukan secara efektif mulai tahun 2018. PSAK 72 merupakan standar yang menganut principles based. Standar ini dibuat secara komprehensif dengan mengatur semua jenis pendapatan yang yang berasal dari kontrak dengan pelanggan. (http://iaiglobal.or.id).

PSAK 72 bertujuan untuk menetapkan standar yang digunakan oleh entitas dalam memberikan informasi yang bermanfaat bagi para pemangku kepentingan yang memuat jumlah, waktu, sifat, dan ketidakpastian pendapatan serta arus kas yang diperoleh dari kontrak dengan pelanggan. Dalam PSAK 72, yang dimaksud dengan pendapatan adalah yang berasal dari kegiatan usaha normal suatu entitas (http://iaiglobal.or.id).

PSAK 72 menggantikan semua standar akuntansi mengenai pengakuan pendapatan yang sudah ada meliputi, PSAK 23 tentang Pendapatan, PSAK 44 tentang Akuntansi Aktivitas Pengembangan Real Estate, PSAK 34 tentang Kontrak Konstruksi, ISAK 27 tentang Pengalihan Aset dari Pelanggan, ISAK 10 tentang Program Loyalitas Pelanggan, serta ISAK 21 tentang Perjanjian Konstruksi Real Estate (http://iaiglobal.or.id). PSAK 72 berlaku untuk semua kontrak dengan pelanggan, kecuali kontrak asuransi, instrumen keuangan, kontrak dalam ruang lingkup sewa, hak atau kewajiban kontraktual lain, serta pertukaran nonmoneter antarentitas dalam jaringan bisnis yang sama (http://iaiglobal.or.id).

Dalam menentukan pengakuan pendapatan, PSAK 72 mengharuskan entitas untuk terlebih dahulu menganalisis transaksi berdasarkan kontrak melalui lima tahap yaitu, 
identifikasi kontrak dengan pelanggan, identifikasi kewajiban pelaksanaan, penentuan harga transaksi, alokasi harga transaksi, dan pengakuan pendapatan pada saat atau ketika suatu entitas sudah menyelesaikan kewajiban pelaksanaannya (http://iaiglobal.or.id).

\section{METODE PENELITIAN}

Penelitian ini menggunakan metode kualitatif dengan pendekatan bibliografi. Pendekatan bibliografi digunakan untuk mengetahui perkembangan penelitian pada topik tertentu agar dapat menemukan kesenjangan penelitian (Villas et al., 2008). Ada tiga proses yang dilakukan dalam penelitian bibliografi meliputi pengumpulan data, persiapan data, dan analisis data (Zoogah \& Rigg, 2014). Pendekatan bibliografi telah digunakan dalam penelitian Hesford et al. (2007) dalam bidang akuntansi manajemen yang menggunakan sampel sebanyak 916 artikel dari sepuluh jurnal pada tahun 1981-2000. Penelitian bibliografi juga telah dilakukan di Indonesia terkait pajak (Herawati \& Bandi, 2017), transfer pricing (Arham et al., 2020), manajemen pendapatan (Suprianto \& Setiawan, 2017), serta adopsi IFRS (Aksan et al., 2019; Ernawati \& Aryani, 2019).

Pendekatan bibliografi dalam penelitian ini diawali dengan mencari berbagai hasil penelitian melalui laman Google Scholar dengan menggunakan kata kunci penerapan/implementasi IFRS 15 atau PSAK 72. Dari hasil pencarian tersebut, penelitian ini mengumpulkan data yang menjadi objek penelitian sebanyak 22 artikel yang terdiri atas 19 artikel jurnal dan 3 artikel prosiding. Kemudian, penelitian ini menganalisis dan memetakan berdasarkan lokasi objek penelitian, topik penelitian, dan sikap objek penelitian terhadap implementasi IFRS 15.

\section{HASIL PENELITIAN DAN PEMBAHASAN}

Ulasan mengenai implementasi IFRS 15 ternyata sudah mulai dilakukan oleh para peneliti sejak tahun 2015. Berdasarkan Gambar 1, jumlah penelitian terkait implementasi IFRS 15 dari tahun ke tahun bersifat fluktuatif. Hasil penelitian tentang implementasi IFRS 15 paling banyak dipublikasikan pada tahun 2017 dan 2019. Setelah itu, jumlahnya mengalami penurunan yang signifikan.

Gambar 1. Pemetaan Berdasarkan Tahun Penerbitan

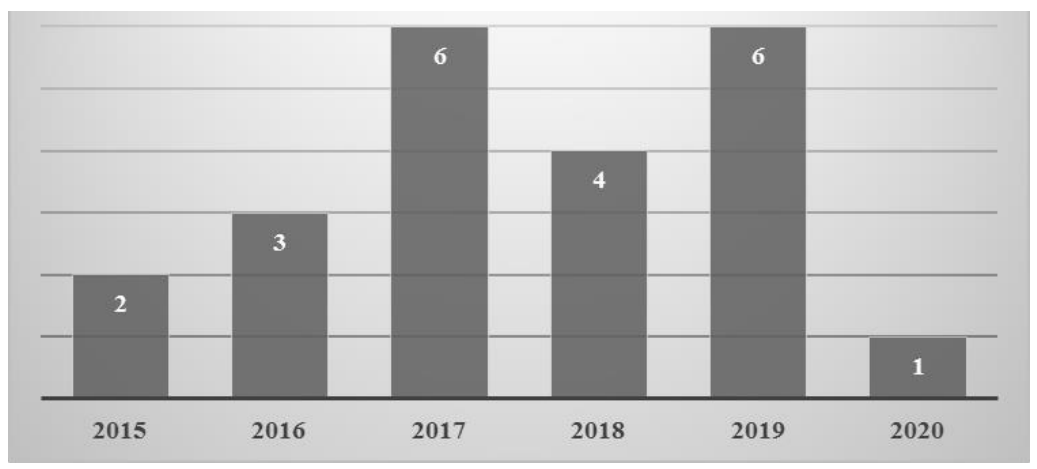

Sumber: Diolah

\section{Pemetaan Berdasarkan Lokasi Objek Penelitian}

Penelitian ini membagi objek penelitian ke dalam lima kelompok besar berdasarkan lokasi objek penelitian, yaitu Indonesia, Asia lainnya, Eropa, Afrika, dan Amerika. Pembagian ini dilakukan agar dapat mengetahui seperti apa hasil-hasil penelitian terkait implementasi IFRS 15 di berbagai kawasan tersebut untuk selanjutnya akan dilakukan pemetaan atau analisis komparatif. Pemetaan hasil penelitian terkait implementasi IFRS 15 dapat dilihat dalam Tabel 1. Tabel 1 memberikan informasi bahwa hasil penelitian terkait implementasi IFRS 15 paling banyak dilakukan di Eropa dan Asia.

Tabel 1. Pemetaan Berdasarkan Lokasi Objek Penelitian 


\begin{tabular}{lr}
\hline Lokasi Objek Penelitian & Jumlah \\
\hline Indonesia & 4 \\
Asia Lainnya & 7 \\
Eropa & 8 \\
Afrika & 2 \\
Amerika & 1 \\
\hline \multicolumn{2}{|c}{ Total } \\
\hline \multicolumn{2}{r}{ Sumber }
\end{tabular}

\section{Hasil Penelitian di Indonesia}

Ada empat hasil penelitian terdahulu yang mengulas tentang implementasi IFRS 15 yang diadopsi ke dalam PSAK 72 di Indonesia. Penelitian pertama dilakukan oleh Yohannes pada tahun 2017 yang mengulas tentang pengaruh komitmen pada organisasi, kompetensi sumber daya manusia, dan going concern terhadap implementasi PSAK 72. Hasil penelitian tersebut memberikan bukti bahwa komitmen pada organisasi dan kompetensi sumber daya manusia mempunyai pengaruh terhadap implementasi PSAK 72. Sementara itu, going concern tidak berpengaruh signifikan terhadap kesiapan implementasi PSAK 72. Penelitian ini menunjukkan bahwa anggota Asosiasi Kontraktor Indonesia (AKI) sudah siap untuk mengimplementasikan PSAK 72 karena memerlukan karyawan yang mempunyai pendidikan, keterampilan, serta pernah mengikuti seminar yang berhubungan dengan kontrak konstruksi. Sementara terkait going concern, perusahaan konstruksi belum memperhatikan hal tersebut sehingga mengakibatkan utang-utang kepada vendor tidak dibayar pada saat jatuh tempo dan perusahaan belum memperhatikan kontrak-kontrak selanjutnya di masa depan (Yohannes, 2017).

Penelitian kedua dilakukan oleh Wisnantiasri pada tahun 2018. Penelitian tersebut bertujuan untuk menguji dampak dari pengumuman PSAK 72 dilihat dari sisi investor melalui reaksi pasar saham. Penelitian ini menggunakan proksi shareholder value. Pengujian yang dilakukan fokus pada perusahaan di sektor industri property, real estate and building construction. Hasil penelitian menunjukkan bahwa pengumuman PSAK 72 mampu menambah shareholder value. Pada PSAK 72, pendapatan konstruksi dapat diakui secara bertahap sesuai kontrak yang mengakibatkan laba atau rugi di industri konstruksi tidak lagi fluktuatif. Investor mengharapkan PSAK 72 dapat meningkatkan kualitas dan keandalan informasi dalam laporan keuangan agar estimasi resiko investasi dapat dikurangi. Dengan demikian, pengambilan keputusan dapat dilakukan secara lebih akurat (Wisnantiasri, 2018).

Penelitian berikutnya dilakukan oleh Bernoully \& Wondabio pada tahun 2019. Tujuan penelitian tersebut yaitu mengulas dampak implementasi IFRS 15 pada laporan keuangan perusahaan telekomunikasi di Indonesia. Penelitian tersebut mencoba menganalisis besarnya dampak implementasi IFRS 15 terhadap proses pengakuan, pengukuran, penyajian, dan pengungkapan pendapatan di perusahaan telekomunikasi serta untuk mengidentifikasi perubahan yang diperlukan karena berlakunya standar ini. Hasil penelitian menunjukkan bahwa implementasi IFRS 15 di PT XYZ tidak hanya akan memengaruhi pengakuan pendapatan dan proses persiapan pelaporan keuangan tetapi juga akan berdampak dan memerlukan perubahan pada lingkungan pengendalian internal, sistem informasi dan teknologi, indikator kinerja utama, proses perhitungan imbalan kerja, dan juga hubungan dengan investor. Implementasi IFRS 15 bukan hanya merupakan tanggung jawab bagian akuntansi, tetapi juga memerlukan koordinasi dan kerja tim yang baik antarunit terkait di PT XYZ dalam melakukan perubahan yang diperlukan (Bernoully \& Wondabio, 2019).

Penelitian terakhir dalam bentuk prosiding dilakukan oleh Veronica, et al. pada tahun 2019. Penelitian tersebut bertujuan untuk mengetahui bagaimana dampak penerapan pengakuan pendapatan sesuai dengan PSAK 72 terhadap kinerja keuangan perusahaan real estate. Penelitian ini dilakukan pada sektor real estate karena dinilai sebagai salah satu sektor yang terdampak cukup signifikan atas terbitnya PSAK 72 dan menggantikan PSAK 44 yang sebelumnya digunakan oleh sektor ini. Hasil penelitian menunjukan bahwa penerapan pengakuan pendapatan sesuai dengan PSAK 72 membuat kinerja keuangan perusahaan terlihat tidak lebih baik jika dibandingkan dengan saat menggunakan standar 
sebelumnya. Pengaturan pada PSAK 72 membuat pendapatan dari kontrak jangka panjang pada perusahaan tidak dapat diakui. Oleh karena itu, nilai pendapatan pada masing-masing perusahaan saat menggunakan PSAK 72 menjadi lebih kecil jika dibandingkan dengan nilai pendapatan yang diakui berdasarkan PSAK 44 (Veronica et al., 2019).

\section{Hasil Penelitian di Negara Asia Lainnya}

Ada tujuh penelitian terdahulu mengenai implementasi IFRS 15 di negara Asia lainnya yang dilakukan di Malaysia, Yordania, Bangladesh, Uni Emirat Arab, Oman, Irak, dan India. Penelitian pertama dilakukan di Malaysia pada tahun 2015 oleh Yingzhee et al. Hasil penelitian tersebut memberikan gambaran tentang persiapan dan persepsi auditor Malaysia tentang IFRS 15. Hasil penelitian mengungkapkan bahwa umumnya akuntan Malaysia yang disurvei masih belum siap untuk mengadopsi IFRS 15 dan mereka merasa bahwa standar tidak mudah diterapkan di berbagai sektor bisnis (Yingzhee et al., 2015).

Pada tahun 2017, Al-Shatnawi melakukan penelitian di Yordania untuk mengeksplorasi tingkat kemungkinan bagi perusahaan industri di Yordania untuk menerapkan IFRS 15 dari sudut pandang penyusun laporan keuangan. Hasil penelitian menunjukkan bahwa perusahaan industri Yordania mungkin dapat berkomitmen terhadap persyaratan untuk pengakuan pendapatan dan pengukuran akuntansi. Akan tetapi, perusahaan-perusahaan tersebut tidak mungkin berkomitmen terhadap persyaratan untuk pengungkapan pendapatan sesuai dengan IFRS 15 karena perusahaan-perusahaan tersebut tidak mengungkapkan informasi kuantitatif dan deskriptif secara memadai dalam kontrak dengan pelanggan. Selain itu, perusahaan-perusahaan tersebut mengalami kesulitan dalam memahami dan menjelaskan persyaratan IFRS 15 serta kurangnya sistem akuntansi yang memadai yang memfasilitasi penerapan akuntansi untuk pendapatan sesuai dengan IFRS 15 (AI-Shatnawi, 2017).

Pada tahun 2018, ada dua penelitian terkait implementasi IFRS 15 di negara Asia lainnya yaitu di Bangladesh dan Uni Emirat Arab. Pertama, Mazumder \& Purohit di Bangladesh melakukan penelitian terkait pengakuan pendapatan atas kontrak jangka panjang berdasarkan IFRS 15 dengan studi kasus pada perusahaan real estate di Bangladesh. Hasil penelitian menunjukkan bahwa perusahaan dilaporkan berkomitmen untuk mengadopsi standar tersebut dan melakukan beberapa persiapan untuk implementasi standar tersebut (Mazumder \& Purohit, 2018). Yang kedua, Trabelsi menganalisis pengaruh penerapan dini IFRS 15 oleh perusahaan real estate di Dubai, Uni Emirat Arab, pada kualitas informasi akuntansi terkait laba dan ekuitas. Hasil penelitian menunjukkan bahwa penerapan dini IFRS 15 memiliki dampak positif yang signifikan dalam mempengaruhi laba dan ekuitas untuk semua perusahaan yang dianalisis. Selain itu, penerapan IFRS 15 membantu dalam memberikan informasi akuntansi yang selaras dengan karakteristik kualitatif dari kerangka konseptual (Trabelsi, 2018).

Sama halnya dengan tahun sebelumnya, pada tahun 2019 juga terdapat dua penelitian terkait implementasi IFRS 15 di negara Asia lainnya yaitu Oman dan Irak. Dalwai, et al. melakukan penelitian terkait respon dari para ahli akuntansi mengenai penerapan IFRS 15 di Oman. Hasil penelitian menunjukkan bahwa IFRS 15 tidak hanya menyebabkan perubahan kebijakan akuntansi tetapi juga mempengaruhi fungsi bisnis dan kemampuan perusahaan untuk mengelola sistem pengendalian internal. Selain itu, IFRS 15 dianggap akan menimbulkan beberapa masalah umum seperti, kolektibilitas, pendefinisian pelanggan, dan pengungkapan sehingga perusahaan harus memahami dampak dari perubahan dan mengembangkan sumber daya yang tepat (Dalwai, et al., 2019). Adapun penelitian di Irak dilakukan oleh Hameed, et al. Penelitian tersebut bertujuan untuk mengetahui pengaruh adopsi IFRS 15 pada pendapatan kontrak dari pelanggan dalam jumlah dan kualitas laba akuntansi. Penelitian ini mengungkapkan bahwa IFRS 15 tidak mempunyai pengaruh signifikan terhadap kualitas laba bersih karena standar pelaporan yang berlaku di Irak tidak sesuai dengan kriteria spesifik dalam IFRS 15 (Hameed, et al., 2019).

Penelitian terbaru mengenai implementasi IFRS 15 di negara Asia lainnya dilakukan oleh Dawane pada tahun 2020. Penelitian ini membahas tentang dampak IFRS 15 terhadap 
sektor real estate dan konstruksi. Hasil penelitian ini menekankan bahwa perusahaan sektor real estate dan konstruksi di India perlu untuk memperhatikan titik pengakuan pendapatan karena terdapat perubahan signifikan terhadap kriteria pengakuan pendapatan. Selain itu, IFRS 15 juga mungkin berdampak pada sejumlah kontrak (Dawane, 2020).

\section{Hasil Penelitian di Eropa}

Di Eropa, ada sembilan penelitian terdahulu yang mengulas tentang implementasi IFRS 15. Kesembilan negara tersebut adalah Rusia, Belgia, Malta, Republik Ceko, Polandia, Swedia, Jerman, dan Italia. Penelitian pertama pada tahun 2015 dilakukan di Rusia oleh Druzhilovskaya \& Druzhilovskaya. Penelitian tersebut bertujuan untuk menganalisis perbandingan antara IFRS 15 dengan standar akuntansi yang berlaku di Rusia. Hasil penelitian menunjukkan bahwa pada saat itu tidak perlu secara aktif dilakukan konvergensi IFRS 15 ke dalam standar akuntansi di Rusia (Druzhilovskaya \& Druzhilovskaya, 2015).

Pada tahun 2016, ada dua penelitian mengenai implementasi IFRS 15 yang dilakukan di Eropa. Yang pertama, di Belgia, penelitian dilakukan oleh Peters yang menunjukkan hasil adanya respon negatif terhadap IFRS 15 karena memberikan beban kerja tambahan tetapi tidak menciptakan nilai tambah. Selain itu, hasil penelitian mengungkapkan adanya kesulitan bagi entitas untuk memahami dan menerapkan IFRS 15 (Peters, 2016). Yang kedua, penelitian dilakukan di Malta oleh Karl. Penelitian tersebut mengevaluasi perubahan dalam perusahaan konstruksi lokal sebagai akibat dari pelaksanaan IFRS 15. Hasil penelitian menunjukkan bahwa perusahaan konstruksi di Malta harus mengevaluasi dampak dari IFRS 15, memperoleh pemahaman yang mendalam tentang prinsip-prinsip yang baru, dan melakukan konsultasi teknis kepada akuntan yang mengerti IFRS (Karl, 2016).

Seperti halnya tahun sebelumnya, pada tahun 2017, ada dua penelitian yang membahas tentang implementasi IFRS 15 di Eropa yaitu di Republik Ceko dan Polandia. Penelitian di Republik Ceko dilakukan oleh Starova et al. untuk menunjukkan implikasi dari penerapan IFRS 15 bagi entitas akuntansi dan memberikan contoh studi kasus perlakuan akuntansi. Hasil penelitian mengungkapkan bahwa IFRS 15 memberikan perubahan terhadap praktik akuntansi saat itu terutama untuk jumlah dan waktu pengakuan pendapatan pada perusahaan yang dipilih. Perubahan yang paling signifikan yaitu terkait dengan alokasi harga transaksi, penjualan dengan hak kembali, dan lisensi dengan hak untuk menggunakan. IFRS 15 memberikan pandangan yang lebih sistematis mengenai pengakuan pendapatan dan membutuhkan pertimbangan profesional dengan tingkat yang lebih tinggi (Starova et al,, 2017). Penelitian di Polandia dilakukan oleh Bauer \& Centorrino yang menganalisis dampak dari IFRS 15 terhadap laporan keuangan bank. Hasil penelitian menemukan bahwa dalam semua kasus yang diteliti, IFRS 15 berdampak terhadap laporan keuangan bank. Akan tetapi, adanya perbedaan penyajian informasi tentang IFRS 15 menimbulkan kendala bagi pengguna laporan keuangan bank (Bauer \& Centorrino, 2017).

Penelitian terkait penerapan IFRS 15 pada tahun 2018 dilakukan oleh Johansson \& Noori di Swedia. Penelitian tersebut mengevaluasi bagaimana perusahaan menerapkan IFRS 15. Dari hasil penelitian ditemukan bahwa ada tiga faktor yang berpengaruh signifikan dalam penerapan IFRS 15 yaitu penetapan tujuan dan rencana aksi, pendidikan dan keterampilan, serta manajer dan komitmen manajemen. Ketiga faktor tersebut memiliki dampak yang signifikan terhadap proses penerapan IFRS 15 pada perusahaan (Johansson \& Noori, 2018).

Pada tahun 2019, ada dua negara di Eropa yang melakukan penelitian terkait penerapan IFRS 15 yaitu Jerman dan Italia. Di Jerman, penelitian dilakukan oleh Haggenmüller yang mengulas masalah dan tantangan utama selama implementasi IFRS 15 dan menilai dampak yang mungkin ditimbulkan pada profitabilitas dan kinerja perusahaan. Hasil penelitian menunjukkan bahwa industri tertentu mengalami kesulitan dalam menerapkan persyaratan pengakuan pendapatan karena panduan yang tidak spesifik sehingga memaksa mereka untuk menggunakan standar di luar IFRS 15. IFRS 15 juga memengaruhi perusahaan dengan model bisnis sederhana karena implementasinya memakan waktu dan biaya. Meskipun tidak ada indikasi yang terdeteksi bahwa manajemen 
laba atau manipulasi mungkin dilakukan terkait dengan penerapan IFRS 15, standar tersebut masih membutuhkan interpretasi dan pertimbangan profesional (Haggenmüller, 2019). Penelitian di Italia dilakukan oleh Tutino, et al. yang mengukur sejauh mana manajemen laba berasal dari adopsi IFRS 15 serta mendeteksi apakah dampaknya akan serupa dalam industri yang berbeda. Hasil penelitian menunjukkan bahwa implementasi IFRS 15 harus dianalisis dengan seksama dan dipantau oleh regulator, serta diadopsi secara benar oleh manajer karena pendapatan yang dihasilkan bisa berdampak pada praktik manajemen laba yang sudah ada (Tutino, et al., 2019).

\section{Hasil Penelitian di Afrika}

Penelitian terkait penerapan IFRS 15 di Afrika dilakukan di dua negara yaitu Mesir dan Afrika Selatan. Penelitian pertama di Mesir dilakukan pada 2016 oleh Khamis. Penelitian tersebut bertujuan untuk mengetahui persepsi pembuat laporan keuangan dan auditor di Mesir terhadap IFRS 15. Penelitian tersebut berfokus pada tingkat kejelasan standar dan kemudahan penerapan di seluruh sektor bisnis yang ada di Mesir. Hasil penelitian menunjukkan bahwa para auditor belum memiliki pemahaman yang konsisten dan mendalam mengenai IFRS 15 karena mereka masih asing dengan aturan baru tersebut dan mereka meyakini bahwa konsep IFRS 15 tidak jelas dan sulit diterapkan di seluruh sektor bisnis yang ada di Mesir. Selain itu, penelitian tersebut menemukan bahwa akuntan dan auditor di Mesir masih belum siap untuk mengadopsi dan tidak memiliki pengetahuan yang cukup tentang IFRS 15 (Khamis, 2016).

Penelitian berikutnya di Afrika Selatan dilakukan oleh Silva pada tahun 2017. Penelitian tersebut bertujuan untuk mengevaluasi dampak implementasi IFRS 15 terhadap perusahaan yang terdaftar di Bursa Efek Johannesburg baik dari segi pelaporan ataupun aspek lain. Dari hasil penelitian ditemukan bahwa penerapan IFRS 15 akan memiliki implikasi yang luas bagi organisasi, tidak hanya atas pelaporan keuangan. IFRS 15 akan membawa perubahan dalam lima bidang utama yaitu, strategi, tingkat kolaborasi, pelatihan, sistem teknologi informasi, serta evaluasi kinerja karyawan dan organisasi (Silva, 2017).

\section{Hasil Penelitian di Amerika}

Hasil penelitian mengenai implementasi IFRS 15 di Amerika hanya ada satu yaitu penelitian Dani, et al. pada tahun 2017. Tujuan penelitian tersebut adalah menganalisis hubungan antara kualitas informasi akuntansi dan adopsi awal IFRS 15 pada perusahaanperusahaan konstruksi yang terdaftar di Bursa Efek Brazil (BM \& F Bovespa). Hasil penelitian menunjukkan bahwa penerapan awal IFRS 15 dianggap memberikan kualitas informasi akuntansi yang positif dan memuaskan. Adopsi IFRS 15 membantu untuk mengurangi bias nonkomparatif dan inkonsistensi yang mungkin ada karena adopsi kriteria akuntansi yang berbeda dalam hal penentuan pendapatan kontrak konstruksi (Dani et al, 2017).

\section{Pemetaan Berdasarkan Topik Penelitian}

Berdasarkan data hasil penelitian mengenai implementasi IFRS 15 pada lima kelompok atau lokasi objek penelitian, penelitian ini melakukan analisis komparatif untuk memetakan berdasarkan topik penelitian. Pemetaan ini dibagi ke dalam tiga kelompok yaitu, persepsi, dampak, dan masalah. Selanjutnya, topik persepsi dipetakan berdasarkan pihak yang memberikan persepsi yang terdiri atas pembuat dan pengguna laporan keuangan. Hal yang sama juga dilakukan terhadap topik dampak dan masalah. Hasil analisis komparatif yang pertama mengenai pemetaan topik penelitian terkait implementasi IFRS 15 disajikan dalam Tabel 2. 
Tabel 2. Pemetaan Berdasarkan Topik

\begin{tabular}{l|c|c|c}
\hline \multicolumn{1}{c}{ Objek } & \multicolumn{3}{c}{ Topik } \\
\cline { 2 - 4 } & Persepsi & Dampak & Masalah \\
\hline Indonesia & V & V & - \\
\hline Asia lainnya & V & V & - \\
Eropa & V & V & V \\
\hline Afrika & V & V & - \\
\hline Amerika & - & V & - \\
\hline
\end{tabular}

Sumber: Diolah

Tabel 2 menunjukkan bahwa hasil penelitian di semua objek telah membahas mengenai dampak dari implementasi IFRS 15. Hal ini berarti dampak dari penerapan standar akuntansi mengenai pendapatan dari kontrak pelanggan tersebut adalah hal yang penting dan menarik untuk diteliti dan diketahui oleh publik. Hal yang hampir sama juga ditemukan pada topik persepsi. Hanya ada satu objek penelitian yang belum pernah membahas tentang persepsi atas penerapan standar baru ini. Hal yang sangat berbeda dapat dilihat pada topik masalah. Hanya satu objek penelitian yang pernah membahas mengenai masalah yang ditemui dalam proses implementasi yaitu hasil penelitian di Eropa. $\mathrm{Hal}$ ini dikarenakan memang di Eropa lebih dulu menerapkan standar ini, sementara di negara lain masih dalam proses adopsi sehingga belum ada penelitian yang mengulas mengenai masalah-masalah yang ditemukan selama implementasi standar.

\begin{tabular}{lcc}
\multirow{2}{*}{ Tabel 3. Pemetaan Berdasarkan Persepsi } \\
\hline \multirow{2}{*}{ Objek } & \multicolumn{2}{c}{ Persepsi } \\
\cline { 2 - 3 } & Pembuat Laporan & Pengguna Laporan \\
\hline Indonesia & $\mathbf{V}$ & - \\
\hline Asia lainnya & $\mathbf{V}$ & $\mathbf{V}$ \\
Eropa & $\mathbf{v}$ & - \\
Afrika & $\mathbf{V}$ & $\mathbf{V}$ \\
Amerika & - & - \\
\hline
\end{tabular}

Sumber: Diolah

Tabel 3 menunjukkan hasil analisis komparatif tentang pemetaan berdasarkan persepsi dilihat dari pihak yang memberikan persepsi atau yang menjadi objek dalam penelitian terdahulu. Berdasarkan Tabel 3 dapat diketahui bahwa persepsi atas implementasi IFRS 15 lebih banyak membahas dari sudut pandang pembuat laporan keuangan. Hal ini dikarenakan standar baru ini memang diperuntukkan bagi entitas pembuat laporan keuangan sehingga penelitian berfokus pada seperti apa persepsi entitas pembuat laporan keuangan dengan adanya standar baru ini.

Tabel 4. Pemetaan Berdasarkan Dampak

\begin{tabular}{l|c|c}
\hline \multirow{2}{*}{ Objek } & \multicolumn{2}{c}{ Dampak } \\
\cline { 2 - 3 } & Pembuat Laporan Pengguna Laporan \\
\hline Indonesia & $\boldsymbol{V}$ & $\boldsymbol{V}$ \\
\hline Asia lainnya & $\mathbf{V}$ & - \\
Eropa & $\mathrm{V}$ & - \\
\hline Afrika & $\mathbf{V}$ & - \\
\hline Amerika & $\mathbf{v}$ & - \\
\hline
\end{tabular}

Sumber: Diolah

Analisis komparatif hasil penelitian mengenai topik dampak dilakukan dengan memetakan berdasarkan pihak yang terkena dampak dari adanya implementasi IFRS 15. Tabel 4 menunjukkan bahwa semua hasil penelitian di lima objek berfokus pada dampak penerapan standar baru ini bagi pembuat laporan keuangan atau entitas pelapor. Hanya satu objek penelitian yang pernah membahas dampak penerapan IFRS 15 bagi pengguna laporan keuangan. Hal ini menimbulkan research gap yang dapat memberikan kontribusi dengan menjadi fokus penelitian berikutnya. 
Tabel 5. Pemetaan Berdasarkan Masalah

\begin{tabular}{l|cc}
\hline \multirow{2}{*}{ Objek } & \multicolumn{2}{c}{ Masalah } \\
\cline { 2 - 3 } & Pembuat Laporan Pengguna Laporan \\
\hline Indonesia & - & - \\
Asia lainnya & - & - \\
Eropa & V & V \\
Afrika & - & - \\
Amerika & - & - \\
\hline
\end{tabular}

Sumber: Diolah

Tabel 5 menunjukkan hasil analisis komparatif tentang pemetaan topik masalah dilihat dari pihak yang mengalami masalah dalam proses implementasi IFRS 15 atau yang menjadi objek dalam penelitian terdahulu. Berdasarkan Tabel 4 dapat diketahui bahwa meskipun baru satu objek yang pernah membahas topik ini, namun telah melihat dari dua sisi yaitu pembuat dan pengguna laporan keuangan. Hal ini berarti baik entitas penyusun laporan keuangan maupun para stakeholder sebagai pengguna laporan keuangan menemukan kendala selama proses implementasi standar baru ini.

\section{Pemetaan Berdasarkan Sikap Objek Penelitian terhadap IFRS 15}

Pemetaan terakhir dalam penelitian ini dilakukan untuk mengetahui bagaimana objek penelitian menyikapi IFRS 15, apakah pro atau kontra. Hasil analisis komparatif yang terakhir mengenai bagaimana objek penelitian menyikapi IFRS 15 (Pro/Kontra) dapat dilihat pada Tabel 6.

Tabel 6. Analisis Komparatif Berdasarkan Sikap Terhadap IFRS 15

\begin{tabular}{l|cc}
\hline \multirow{2}{*}{ Objek } & \multicolumn{2}{c}{ Sikap terhadap IFRS 15 } \\
\cline { 2 - 3 } & Pro & Kontra \\
\hline Indonesia & V & V \\
\hline Asia lainnya & V & V \\
Eropa & V & V \\
Afrika & - & V \\
\hline Amerika & V & - \\
\hline
\end{tabular}

\section{Sumber: Diolah}

Mayoritas sikap objek penelitian terhadap implementasi IFRS 15 masih belum jelas. Hal ini dapat diketahui dari objek penelitian yang lebih banyak menunjukkan sikap berada di dua sisi yaitu pro dan kontra. Sikap pro terhadap implementasi IFRS 15 disebabkan oleh beberapa alasan antara lain, IFRS 15 dapat meningkatkan kualitas dan keandalan informasi dalam laporan keuangan (Wisnantiasri, 2018), membantu dalam memberikan informasi akuntansi yang selaras dengan karakteristik kualitatif dari kerangka konseptual (Trabelsi, 2018), serta membantu untuk mengurangi bias nonkomparatif dan inkonsistensi yang mungkin ada karena adopsi kriteria akuntansi yang berbeda dalam hal penentuan pendapatan kontrak konstruksi (Dani et al., 2017). Sementara itu, beberapa alasan yang menyebabkan timbulnya sikap kontra terhadap implementasi IFRS 15 yaitu, IFRS 15 membuat kinerja keuangan perusahaan terlihat tidak lebih baik jika dibandingkan dengan saat menggunakan standar sebelumnya (Veronica et al., 2019), sulit dipahami dan diterapkan (Yingzhee et al., 2015; Al-Shatnawi, 2017; Dalwai, et al., 2019; Bauer \& Centorrino, 2017; Khamis, 2016), tidak sesuai dengan konteks pelaporan yang berlaku di suatu negara (Hameed et al., 2019), serta membutuhkan waktu dan biaya yang tidak sedikit (Haggenmüller, 2019). Adanya pro dan kontra tersebut menunjukkan bahwa implementasi standar akuntansi yang baru ini masih perlu terus dilakukan kajian termasuk penyempurnaan agar dapat memenuhi kepentingan pihak-pihak yang terkait.

\section{KESIMPULAN DAN SARAN}

Penelitian ini dilakukan untuk menganalisis dan memetakan berbagai hasil penelitian terkait implementasi IFRS 15 tentang Pendapatan dari Kontrak dengan Pelanggan agar 
dapat mengetahui fokus penelitian di berbagai negara di dunia baik yang ditinjau dari segi topik penelitian maupun sikap (pro/kontra) terhadap standar ini.

Hasil penelitian ini menunjukkan bahwa topik penelitian yang paling banyak dibahas adalah tentang dampak implementasi IFRS 15. Hasil penelitian dengan topik persepsi dan dampak lebih berfokus pada pembuat laporan keuangan. Sementara itu, penelitian dengan topik masalah telah memberikan sudut pandang dari dua sisi (pembuat dan pengguna laporan keuangan). Hasil penelitian menunjukkan bahwa mayoritas sikap objek penelitian terhadap implementasi IFRS 15 masih belum jelas karena menunjukkan sikap berada di dua sisi yaitu pro dan kontra.

Penelitian ini diharapkan dapat memberikan gambaran secara holistik seperti apa penerapan standar akuntansi mengenai pendapatan dari kontrak dengan pelanggan di seluruh dunia. Penelitian ini juga diharapkan dapat menunjukkan adanya research gap yang dapat dijadikan bahan riset selanjutnya bagi para akademisi dan memberikan masukan bagi regulator dalam penyusunan standar akuntansi di masa depan.

Penelitian ini hanya menggunakan pendekatan kualitatif yang berfokus pada telaah pustaka. Penelitian selanjutnya diharapkan dapat menggunakan metode kualitatif melalui wawancara untuk mengumpulkan pendapat para ahli dari seluruh dunia terkait implementasi IFRS 15. Selain itu, penelitian ini hanya menggunakan data sekunder dengan jumlah sampel yang terbatas. Penelitian berikutnya dapat menambah jumlah sampel penelitian yang mencakup seluruh negara di dunia yang menerapkan IFRS 15 agar dapat dilakukan analisis menggunakan pendekatan kuantitatif.

\section{DAFTAR PUSTAKA}

Ahmed, K., Chalmers, K., \& Khlif, H. (2013). A Meta-Analysis of IFRS Adoption Effects. The International Journal of Accounting, 48(2), 173-217.

Al-Shatnawi, H. M. (2017). The Possibility of the Jordanian Industrial Corporations to Apply the IFRS No. 15. Asian Journal of Finance \& Accounting, 9(1).

Aksan, I., Setiawan D., \& Gantyowati E. (2019). Research Development Related to Implementation of Financial Accounting Standards in Indonesia. International Journal of Economics, Business, and Accounting Research (IJEBAR), 3(4), 420-434.

Arham, A., Firmansyah, A., \& Nor, A. M. E. (2020). Penelitian Transfer Pricing di Indonesia: Sebuah Studi Kepustakaan. Jurnal Online Insan Akuntan, 1(1), 57-72.

Bauer, K. \& Centorrino, G. (2017). Financial Statements of Banks as a Source of Information about Implementation of IFRS 15: The Evidence from Poland. Journal of Modern Accounting and Auditing, 13(6), 235-248.

Bernoully, M. \& Wondabio, L. S. (2019). Impact of Implementation of IFRS 15 on the Financial Statements of Telecommunication Company (Case Study of PT XYZ). Advances in Economics, Business, and Management Research, 9.

Burns, N. \& Grove, S. K. (1993). The Practice of Research: Conduct, Critique, and Utilization (Second Edition). Philadelphia: W. B. Saunders Company.

Dalwai, T., Chugh, G., Dinesh, S., \& Mohammadi, S. S. (2019). Oman's Response to the New Accounting Standard: IFRS 15 Revenue from Contracts with Customers. Conference Paper.

Dani, A. C. (2017). Early Adoption of the Effect of IFRS 15 on the Quality of Accounting Information. Reflexão Contábil, 36(2), 131-146.

Daske, H. (2006). Economic Benefits of Adopting IFRS or US-GAAP-Have the Expected Cost of Equity Capital Really Decreased?. Journal of Business Finance \& Accounting, 33, 329-373.

Dawane, S. K. (2020). IFRS and Real Estate Sector in India. Our Heritage, 68, 25.

Druzhilovskaya, T. Y. \& Druzhilovskaya, E. S. (2015). мсфо (IFRS) 15: новые требования и их соотношение с российскими стандартами бухгалтерского учета. международные стандарты, 15, 357.

DSAK-IAI. 2015. Kerangka Konseptual Pelaporan Keuangan. Ikatan Akuntan Indonesia.

Efferin, S. \& Rudiawarni, F. A. (2014). Memahami Perilaku Stakeholders Indonesia dalam Adopsi IFRS: Tinjauan Aspek Kepentingan, Bahasa, dan Budaya. Jurnal Akuntansi 
dan Keuangan Indonesia, 11(2), 138-164.

Ernawati, D. \& Aryani, Y. A. (2019). Empirical Evidence of IFRS Studies in Indonesia. Jurnal Akuntansi dan Auditing Indonesia, 23(2), 65-77.

Evans, L., Gebhardt, G., Hoogendoorn, M., Marton, J., Di Pietra, R., Mora, A., \& Wagenhofer, A. (2005). Problems and Opportunities of an International Financial Reporting Standard for Small and Medium-Sized Entities. The EAA FRSC's Comment on the IASB's Discussion Paper. Accounting in Europe, 2(1), 23-45.

Farcane, N. (2019). Perceptions Regarding the Impact of IFRS 15 - Illustrative Examples Step by Step. Audit Financiar, 17(2).

Ghaniy, A. P. (2018). Studi Komparatif Pengakuan Pendapatan Berdasarkan PSAK 23 dan ED PSAK 72 serta Dampaknya Terhadap Kinerja Keuangan Perusahaan Telekomunikasi. Yogyakarta: Universitas Gadjah Mada.

Haggenmüller, S. (2019). Revenue Recognition under IFRS 15: A Critical Evaluation of Predefined Purposes and Implications for Improvement. Germany: University of Gloucestershire.

Hameed, A. M., Al-taie, B. F. K., \& Al-Mashhadani, B. N. A. (2019). The Impact of IFRS 15 on Earnings Quality in Businesses such as Hotels: Critical Evidence from the Iraqi Environment. African Journal of Hospitality, Tourism and Leisure, 8(4).

Herawati, N., \& Bandi, B. (2017). Dua Puluh Tahun Riset Perpajakan dalam Akuntansi: Suatu Studi Bibliografi. Jurnal Akuntansi dan Keuangan, 19(2), 102-121.

Hesford, J. W., Lee, S. S., Stede, W. A. Van Der, \& Young, S. M. (2007). Management Accounting: A Bibliographic Study. Handbook of Management Accounting Research, 13-26.

International Accounting Standards Board. (2014). Project Summary and Feedback Statement in IFRS 15 Revenue From Contracts with Customers. London: IASB.

Johansson, E. \& Noori, J. (2018). Implementering av IFRS 15: Ur tre IFRS-redovisande foretags perspektiv. Kandidatuppsats $i$ Företagsekonomi, 15(3).

Karl, S. B. (2016). The impact of IFRS 15 on the Local Construction Industry. Malta: LUniversita ta' Malta.

Khamis, A. M. (2016). Perception of Preparers and Auditors on New Revenue Recognition Standard (IFRS 15): Evidence from Egypt. Journal of Accounting and Business Dynamics, 3(2).

Mazumder, B. C., \& Purohit, K. K. (2018). Revenue recognition for long-term contracts under IFRS 15: An analysis with reference to the real estate: Companies in Bangladesh. Indian Journal of Accounting, 50(2).

Peters, M. (2016). The New IFRS 15 Standard : Implementation Challenges for Belgian companies. Belgia: ULG Library.

Pratama, A. \& Wahyuni, E. T. (2015). Tarik Ulur Tanggal Efektif IFRS. Akankah IASB Tunduk pada US FASB?. Majalah Akuntan Indonesia, Juni-Juli.

Silva, I. D. S., (2017). An evaluation of the impact of IFRS 15 on JSE-Listed companies. South Africa: Wits Institutional.

Starova, M., Cermakova, H., Lorinczova, E., Navratilova, M., \& Beranova, M. (2017). Possible Impacts of Application of the New Accounting Standard IFRS 15 Revenue from Contracts with Customers: A Case Study. The International Scientific Conference INPROFORUM, Ceské Budejovice, 196-201.

Suprianto, E., \& Setiawan, D. (2017). Manajemen Laba di Indonesia: Sebuah Studi Bibliografi. Jurnal Keuangan dan Perbankan, 21(040), 287-301.

Trabelsi, N. S. (2018). IFRS 15 Early adoption and Accounting Information: Case of Real Estate Companies in Dubai. Research Article, 22(1).

Tutino, M., Regoliosi, C., Mattei, G., Paoloni, N., \& Pompili, M. (2019). Does the IFRS 15 impact earnings management? Initial evidence from Italian listed companies. African Journal of Business Management, 13(7), 226-238.

Veronica, Lestari, U. P., \& Metekohy, E. Y. (2019). Analisis Dampak Penerapan Pengakuan Pendapatan Berdasarkan PSAK 72 terhadap Kinerja Keuangan Perusahaan Real Estat di Indonesia yang Terdaftar di Bursa Efek Indonesia Tahun 2018. Prosiding $10^{\text {th }}$ Industrial Research Workshop and National Seminar. 
Villas, M. V., Macedo-Soares, T. D. L. van A. de, \& Russo, G. M. (2008). Bibliographical Research Method for Business Administration Studies: A Model Based on Scientific Journal Ranking. Brazilian Administration Review, 5(6), 139-159.

Wahyuni, E. T., Puspitasari, G., \& Puspitasari, E. (2020). Has IFRS improved Accounting Quality in Indonesia? A Systematic Literature Review of 2010-2016. Journal of Accounting and Investment, 21(1), 19-44.

Wisnantiasri, S. N. (2018). Pengaruh PSAK 72: Pendapatan dari Kontrak dengan Pelanggan terhadap Shareholder Value (Studi pada Perusahaan Sektor Property, Real Estate, and Building Construction). Widyakala, 5(1), 60-65.

Yaacob, N., \& Che-Ahmad, A. (2012). Audit Fees After IFRS Adoption: Evidence from Malaysia. Eurasian Business Review, 2(1), 31-46.

Yingzhee, L., Susela, S. D., \& Nurmazilah, M. (2015). Perception of Auditors and Preparers on IFRS 15: Evidence from Malaysia. Advanced Science Letters, 21(6), 1781-1785.

Yohannes. (2017). Faktor-faktor yang Mempengaruhi Kesiapan Implementasi PSAK 72 Pendapatan dari Kontrak dengan Pelanggan (Studi pada Anggota AKI 2017 di Jakarta). Jakarta: Universitas Mercu Buana.

Yurisandi, T., \& Puspitasari, E. (2015). Financial Reporting Quality-Before and After IFRS Adoption Using NiCE Qualitative Characteristics Measurement. Procedia-Social and Behavioral Sciences, 211, 644-652.

Zoogah, D. B., \& Rigg, J. S. (2014). Advancing Research Methodology in the African Context: Techniques, Methods, and Designs Article Information. Research Methodology in Strategy and Management, 8, 189-213.

https://ekonomi.bisnis.com/read/20190808/47/1134399/rei-psak-72-masih-bermasalah diakses pada tanggal 7 Februari 2020.

https://finansial.bisnis.com/read/20190328/11/905482/menakar-signifikansi-penerapanstandar-akuntansi-baru-terhadap-korporasi-indonesia diakses pada tanggal 7 Februari 2020.

http://iaiglobal.or.id/v03/berita-kegiatan/detailarsip-832 diakses pada tanggal 7 Februari 2020.

https://news.ddtc.co.id/pengaruh-penerapan-psak-72-terhadap-perpajakan-17279 diakses pada 7 Februari 2020. 